\title{
Using Mobile Technology in Language Learning: Merits and Demerits
}

\author{
Radin Honarzad \\ Department of Foreign Languages, Islamic Azad University, Shiraz Branch, Iran
}

\begin{abstract}
The number of mobile users is expected to surpass the 5 billion mark by the end of 2019, worldwide ("Global Mobile Landscape," 2016). The ubiquity and portability of mobile technology have opened up new horizons for language learning and teaching (e.g., McCarty, Sato \& Obari, 2017; Bradley, 2015; El Hariry, 2015). The focus of this study is to shed light on the possible merits and demerits of mobile devices for language learning. Understanding these merits and demerits will increase the success rate of mobile technologies integration into educational settings. Teachers and students have always been interested in finding new paths that may lead to enjoyable language learning (e.g., using various online/offline resources and educational mobile apps). However, as it will be discussed in detail, a number of issues exist regarding the demerits of MALL such as technical problems, distractions and so forth. Altogether, we can safely say that the merits of MALL outweigh its demerits because technology is constantly evolving and some of the current demerits will probably disappear in the future. Keywords: MALL (Mobile Assisted Language Learning), mobile learning, m-learning, mobile technology
\end{abstract} DOI: $10.7176 / \mathrm{JEP} / 10-1-01$

\section{Introduction}

E-learning first emerged during the late $80 \mathrm{~s}$ and in the early $90 \mathrm{~s}$, and afterwards, computer-assisted language learning (CALL) was introduced in the mid-90s (Karjo, 2018; Hashemi, Azizinezhad, Najafi \& Nesari, 2011). With the accelerated pace of technology after 2000s, and specially with numerous mobile hardware innovations after 2010 (e.g., introduction of first-generation iPad and Galaxy S), which minimized some of the old-time shortcomings of former devices such as small screens and insufficient storage, students and teachers became more intrigued to incorporate these new powerful tools with learning and teaching. It is safe to say that desktop computer dominance over technology-based language learning has faded and people are beginning to use their everyday handheld mobile devices such as smartphones, tablets and laptops to learn languages in new ways. We have come a long way since the 2010 era, and the processing power of handheld devices has grown exponentially. Over these years the mobile technology has become more affordable and ubiquitous due to the demand for, multitasking (running multiple applications, all at once), the need to run the latest operating systems and their components smoothly, and executing resource-hungry apps such as graphically demanding games and running multiple social media apps (e.g., Facebook Messenger, WhatsApp, Telegram, Instagram and Skype) simultaneously.

The technological breakthroughs mentioned above have opened a new door to freedom in learning anytime and anywhere via handheld devices which we now call mobile learning (M-learning) (Kukulska-Hulme, Sharples, Milrad, Arnedillo-Sánchez, \& Vavoula, 2009; Kukulska-Hulme \& Shield, 2007). M-learning is considered the next generation of e-learning, and Mobile Assisted Language Learning (MALL) is a subarea of the growing field of M-learning, and it deals with the use of mobile technology in language learning (CzerskaAndrzejewska, 2016). Kukulska-Hulme (2012) defined MALL as the use of mobile technologies in language learning, especially in situations where device portability offers specific advantages including ready access to relevant help or information; more flexible use of time and space; adaptation to personal habits, motivation and preferences; continuity between learning in different settings; and greater opportunity for continued language practice while carrying out everyday activities such as walking, waiting or commuting. Language learning methods have changed continuously throughout history, and as technology evolves, learning methods will alter accordingly. With this introduction in mind, the main aim of the article is to provide acquaintance with the merits and demerits of using mobile technologies in language learning.

\section{Merits}

There have been several studies pointing out the benefits of mobile technology for language learning for both inside and beyond the classroom borders (e.g. Kukulska - Hulme, Lee \& Norris 2017; Luís, 2018). These merits include a wide range of possibilities that continuously evolve, so the researcher will try his best to mention as many of them as possible at the time of conducting this study.

Chen et al., 2002 and Curtis et al., 2002 have denoted five important characteristics of mobile and ubiquitous learning which are also deemed as benefits of m-learning and are also implemented in MALL:

- Permanency: Learners may never lose their work unless it is intentionally deleted. Moreover, all the learning processes are continuously recorded. 
- Accessibility: Learners have access to their documents and data such as videos from anywhere. Information is provided based on their requests, so learning is self-directed.

- Immediacy: Wherever learners are, they can get access to any information right away. Therefore, learners can solve problems on the spot or record the questions and look for the answer later. Internet Access through mobile devices gives students the ability to search for any information in a range of multimedia formats instantly.

- Interactivity: Learners can interact with teachers, peers and experts in synchronous or asynchronous communication formats. Thus, informers are reached easier, and knowledge becomes more attainable than before. Moreover, the primary function of mobile devices has been always for social purposes, as opposed to studying purposes. When looking at the various installed apps on mobile devices, there will always be apps for bilateral or group communication, such as Skype, WeChat, WhatsApp, Snapchat, Facebook Messenger and Telegram.

- Situating of instructional activities: Learning could be embedded in everyday life. Problems encountered by learners and the required knowledge for solutions are presented in their natural and authentic forms. This helps language learners to use their daily life experiences as opportunities to learn new things.

In a similar line of study, Klopfer et al. (2002) classified another five significant advantages of mobile devices that are utilised today by many language learners across the globe:

- Portability: Mobile devices can be taken to various places in the bus, train, classrooms and outside due to their relatively compact size and lightweight, this capability is vital as it may even help learners with some disabilities.

- Collaboration: Mobile devices make data exchange and collaboration possible among learners. Some students who may be shy in real-life classroom situations, might do more collaborations in a social networking mobile environment. The possibility of exchanging knowledge, skills, experiences, attitudes, and expressing ideas through collaboration enables several students work together on assignments even while at distant locations.

- Context sensitivity: Data on mobile devices can be gathered and responded uniquely to the proportionate location and time. What this means is that linguistically challenging encounters that could not be predicted can change to an informal learning context via online resources and apps accessed through mobile technology.

- Connectivity: Mobile devices can be easily connected to another device via wifi, Bluetooth, data collection devices and shared networks so learners can share their data directly and conveniently among each other and with their teachers.

- Individuality: Activity platforms can be customised for each learner to cater to their needs.

In addition to the items discussed above, recent studies have suggested that various language learning apps such as Busuu and Duolingo, will foster the development of learner autonomy (e.g. Rosell-Aguilar, 2018; Vesselinov \& Grego, 2012).

- Autonomy: Learners will be in charge of their own learning and will have greater control over various aspects of their learning via mobile apps.

Using mobile technology and online resources accessed via mobile devices, learners will be able to choose what they learn, how, when and where they learn, and they can even decide how to assess their own learning (Kondo et al., 2012; Sha, Looi, Chen \& Zhang, 2012).

- Self-regulation: Mobile technologies enable learners to plan, direct, monitor and evaluate their language learning based on their own pace of learning and cognitive ability. Additionally, learning platforms such as Moodle and Mobile Audience Response System (MOARS) can automatically provide immediate feedback and scores to students and inform teachers about their progress.

Another useful feature of mobile devices for language learning is the push and pull mechanism (Stockwell \& Hubbard, 2013). The pull mechanism happens when learners gain access to learning materials by their free will without any interference from outside. Conversely, the push mechanism happens when the information is forced directly to the learners and can even be appeared immediately on the device's screen as a notification. The pushed data is mainly in the multimedia format such as text messages, videos, audio files and pictures (e.g., Plana, et. al, 2013; Fattah, 2015; Kennedy \& Levy, 2008; Stockwell 2013; Alemi, Sarab, Anani \& Lari, 2012).

- Push/pull mechanism: While students may pull any data at their own will, learning materials in multimedia format can be pushed directly to them via messenger apps such as Whatsapp and Telegram or through other functionalities such as e-mail, short message service (SMS) and multimedia messaging service (MMS).

Besides the points mentioned above, there could be other potential merits in using mobile technology for language learning that some of them are also briefly alluded to by Hashemi et al. (2011) and will be elaborated 
on by the researcher below:

- Increased engagement: Millennials are very dependent on their mobile devices and, this could be recognized as an opportunity for language material developers and learners alike to use numeral possibilities of mobile technology for language learning.

- Increased motivation: Mobile devices have many unique characteristics such as time/space flexibility, easy access to materials that are of interest for learners and user-friendliness due to touch screen technology and flexible operating systems; therefore there is a great chance that these qualities also increase language learning motivation.

- Bridging the digital gap: According to specifications, mid-range mobile phones are becoming more and more flagship like, but at the same time maintaining affordability with a reasonable price to performance ratio. This means that the number of learners who can gain access to cutting-edge mobile technology will increase exponentially. At the time of writing this article, mobile technology's performance is on par with most of the desktop computers, but with much more built-in functionalities and much less costs, these merits will undoubtedly expand the horizons of MALL in the near future.

- Capturing the moment: Learners can record any piece of information with their mobile devices and use them for educational purposes at a later time. For example, students might record in-class teachertalk and teacher/student interactions in a traditional language classroom via the audio/video recorder functionality of a mobile device and then listen/watch the recorded material on the way back home or at leisure time to catch up on any missed points during the in-class time or to reflect on the time spent during the class.

\section{Demerits}

In the previous part of the article, we looked into the merits of using mobile technology for language learning but these technologies are not void of demerits. Although some of these demerits are manageable and might even disappear over time due to non-stop development of mobile technologies, other demerits cannot be easily managed.

- Distractions: According to Chartrand (2016), some teachers refuse the idea of using mobile devices in the classroom altogether and claim that it will cause too many distractions. They insist that students may spend their time doing unrelated tasks such as texting and socialising with friends, watching videos and surfing through materials that are not related to the lesson (Tindell \& Bohlander, 2012). It is maintained that test performance is significantly lower among students who are distracted by their mobile devices doing non-class-related tasks during a class session due to lack of concentration (Chaklader \& Bohlander 2009). Additionally, teachers might also get distracted by student's action if, for example, a student is playing a multiplayer online game instead of paying attention to the teacher (Tindell \& Bohlander, 2012).

- Technical Problems: Some teachers may struggle with information and communication technology (ICT) skills and these skills are required both for class preparation and lesson planning stages and also while delivering the lesson during the class time. The same is true for some learners, and adequate instructions must be provided to them during the session that might waste valuable class time. Some other technical issues that may arise are network failure and device malfunction during the class (Chartrand, 2016).

- Reduction of face-to-face communication: Nowadays, most students are dominated by their mobile devices and lack interpersonal skills (Agrawal, 2017; Drouin, Kaiser \& Miller, 2015), which contributes to the alienation of students in the classroom. Therefore, some teachers believe those language learners should spend in-class time on face-to-face group activities that contribute to the development of reallife social interactions.

- Outdated technologies: As technology develops rapidly and incessantly, some of the older devices may need replacement due to outdated software and sluggish hardware. In the past, mobile devices used to have small screens and keypads with no touchscreen capabilities (e.g., Czerska-Andrzejewska, 2016; Bachore, 215). Similarly, they lacked enough storage space and their hardware capabilities such as processing power, and random access memory (RAM) amount were highly limited. Consequently, those old devices are rarely used today and are being replaced by new technology. This trend will continue into the foreseeable future, so mobile devices will need replacement and upgrade after a few years of usage.

- Ethical issues: Today, mobile devices are able to record high-quality video and audio formats for a prolonged period with just a few taps and they can also send and receive all types of multimedia files including photos instantly. These capabilities raise some ethical concerns regarding using mobile technologies inside the classroom because audio and video could be recorded during the session without 
the consent of teacher or students and there is also a higher chance of cheating to take place while doing textbook exercises and during exams (e.g., Fackler, 2011).

- Costliness: Although technologically advanced mid-range mobile devices have become more affordable during the past few years, they are still expensive for some students especially in certain parts of the less developed countries. There is also another problem with the high cost of mobile Internet across those regions ("Africa is the continent," 2018) and sometimes hardware replacements and repairs are not that cheap either (Chartrand, 2016).

\section{Conclusion and Discussion}

Mobile technology advancements have been revolutionising our world with an accelerated pace since the 2010s, and the field of education and language learning have been no exception to this wave of change. In a distant the past, if an English learner in a developing country such as Iran, wanted to watch an English TV programme, listen to an English radio channel or read an article in English, would be faced with numerous difficulties. First, most of English TV channels and authentic multimedia were accessible only through satellite equipment which on the one hand were very expensive and on the other hand using satellite receivers in Iran is to this day prohibited by law. Moreover, accessing international radio channels was not that easy either because the signals were weak and the number of English language broadcasters was limited. Finally, it was next to impossible for language learners to get their hands on a recently published issue of for instance Time Magazine or Forbes to get access to authentic reading materials. However, the advent of computers, the Internet and lastly mobile technologies and their latest developments over the current decade have made all those actions which seemed impossible one day, a reality that can happen at the palm of a language learner's hand in a fraction of a second, not only in Iran but all over the world.

Using mobile devices for language learning has both merits and demerits. In this article, we discussed both sides and attempted to provide updated views and discussed issues that were not addressed by similar preceding studies (e.g., Miangah \& Nezarat 2012; Hashemi et al., 2011). The merits as are reported in detail, included 'Permanency', 'Accessibility', 'Immediacy', 'Interactivity', 'Situating of instructional activities', 'Portability', 'Social interactivity', 'Context sensitivity', 'Connectivity', 'Individuality', 'Autonomy', 'Self-regulation', 'Push/pull mechanism', 'Increased engagement', 'Increased motivation', 'Bridging the digital gap' and 'Capturing the moment'. However, there exist some demerits as well, including 'Distractions', 'Technical Problems', 'Reduction of face-to-face communication', 'Outdated technologies', 'Ethical issues' and 'Costliness'.

Knowledge of these merits and demerits may be useful to language teachers and administrators before trying to incorporate MALL into classrooms in order to minimise the probable adverse outcomes. According to Hashemi et al. (2011) and Díaz-Vera (2012), m-learning could be a useful tool for particularly involving young adults in learning, where traditional methods have failed because MALL generates flexibility across formal and informal settings. However, MALL enables learners to act in self-determined and autonomous ways, and it is the role of teachers to set boundaries, and design lesson plans to make a clear distinction for activities done through MALL inside and outside the classroom (Kukulska-Hulme, 2013; et al., 2017). Furthermore, Chun (2001) and Heift (2002) argue that before implementing MALL, teachers should consider learner differences and that their lesson design should cater to a range of different learning styles. Additionally, Stockwell (2013) argues that teachers should account for the limitations of learners' affordances and the environment in which the device will be used and try their best to reduce distractions and interruptions. It is also essential that teachers boost their acquaintance with emerging technologies regularly and make adjustments to their teaching methodologies in order to be able to take advantage of upcoming MALL features and to provide necessary guidance to their students on how to efficiently do the activities and tasks via MALL. All in all, we can conclude that the merits of MALL outweigh its demerits because technology is constantly evolving and some of the demerits that exist today will probably disappear in the future.

\section{References}

Africa is the continent with the most expensive mobile internet in the world. (2018, November 5). Retrieved from https:/hybridtechcar.com/2018/11/05/africa-is-the-continent-with-the-most-expensive-mobileinternet-in-the-world/

Agrawal, A. (2017, May 4). Millennials Are Struggling With Face To Face Communication: Here's Why. Retrieved from https://www.forbes.com/sites/ajagrawal/2017/05/04/millennials-are-struggling-with-face-toface-communication-heres-why/\#3e3e3d7126e8

Alemi, M., Sarab, M. R. A., \& Lari, Z. (2012). Successful learning of academic word list via MALL: Mobile Assisted Language Learning. International Education Studies, 5(6), 99-109.

Bachore, M. M. (2015). Language learning through mobile technologies: an opportunity for language learners and teachers. Journal of Education and Practice, 6(31), 50-53. 
Bradley, L. (2015). The Mobile Language Learner-Use of Technology in Language Learning. J. UCS, 21(10), 1269-1282.

Brown, Elizabeth J. 2010. Education in the wild: contextual and location - based mobile learning in action. A report from the STELLAR AlpineRendez - Vous workshop series, edited by Elizabeth Brown. Nottingham, UK: University of Nottingham, Learning Sciences Research Institute (LSRI).

Chaklader, A., \& Bohlander, R. W. (2009). The effects of text messaging on attention. In meeting of the Eastern Psychological Association, Pittsburgh, PA.

Chartrand, R. (2016). Advantages and Disadvantages of Using Mobile Devices in a University Language Classroom, 1-13. Retrieved January 10, 2019, from https://swsu.ru/sbornik-statey/pdf/gaiken23 1-13.pdf

Chen, Y.S., Kao, T.C., Sheu, J.P. and Chiang, C.Y. (2002) 'A mobile scaffolding-aid-based bird-watching learning system', Proceedings of IEEE International Workshop on Wireless and Mobile Technologies in Education (WMTE'02), IEEE Computer Society Press, pp.15-22.

Chun, D. (2001). L2 reading on the web: Strategies for accessing information in hypermedia. Computer Assisted Language Learning, 14(5), 367-403.

Curtis, M., Luchini, K., Bobrowsky, W., Quintana, C. and Soloway, E. (2002) 'Handheld use in K-12: a descriptive account', Proceedings of IEEE International Workshop on Wireless and Mobile Technologies in Education (WMTE'02), IEEE Computer Society Press, pp.23-30.

Czerska-Andrzejewska, D. (2016). Mobile assisted language learning. Zeszyty Glottodydaktyczne, 6, 43-52.

Díaz-Vera, J. (Ed.) 2012. Left to my own devices: Learner autonomy and mobile-assisted language learning innovation and leadership in English language teaching (pp. 197212). Bingley, UK: Emerald Group.

Drouin, M., Kaiser, D., \& Miller, D. A. (2015). What's All the Buzz About?. The Wiley Handbook of Psychology, Technology, and Society, 192.

El Hariry, N. A. (2015). Mobile phones as useful language learning tools. European Scientific Journal, ESJ, 11(16).

Fackler, M. (2011, March 1). Internet Cheating Scandal Shakes Japan Universities. Retrieved from http://www.nytimes.com/2011/03/02/world/asia/02japan.html?_r=0

Fattah, S. F. E. S. A. (2015). The Effectiveness of Using WhatsĀpp Messenger as One of Mobile Learning Techniques to Develop Students' Writing Skills. Journal of Education and Practice, 6(32), 115-127.

Global Mobile Landscape 2016: A Country-by-Country Look at Mobile Phone and Smartphone Usage. (2016, November 16). Retrieved from https://www.emarketer.com/Report/Global-Mobile-Landscape-2016Country-by-Country-Look-Mobile-Phone-Smartphone-Usage/2001859

Hashemi, M., Azizinezhad, M., Najafi, V., \& Nesari, A. J. (2011). What is mobile learning? Challenges and capabilities. Procedia-Social and Behavioral Sciences, 30, 2477-2481.

Heift, T (2002). Learner control and error correction in ICALL: Browsers, peekers, and adamants. CALICO Journal, 19(2), 295-313.

Karjo, C. H., \& Andreani, W. (2018, May). Learning Foreign Languages With Duolingo and Memrise. In Proceedings of the 2018 International Conference on Distance Education and Learning (pp. 109-112). ACM.

Kennedy, C., \& Levy, M. (2008). L'italiano al telefonino: Using SMS to support beginners' language learning. $\operatorname{ReCALL}, 20(3), 315-330$.

Klopfer, E., Squire, K., \& Jenkins, H. (2002). Environmental detectives: PDAs as a window into a virtual simulated world. In Wireless and Mobile Technologies in Education, 2002. Proceedings. IEEE International Workshop on (pp. 95-98). IEEE.

Kondo, M., Ishikawa, Y., Smith, C., Sakamoto, K., Shimomura, H., \& Wada, N. (2012). Mobile assisted language learning in university EFL courses in Japan: Developing attitudes and skills for self-regulated learning. ReCALL, 24(2), 169-187.

Kukulska-Hulme, A. (2012). Language learning defined by time and place: A framework for next generation designs.

Kukulska-Hulme, A. (2013). Mobile-assisted language learning. In C. Chapelle (Ed.), The encyclopedia of applied linguistics (pp. 3701-3709). New York: Wiley.

Kukulska-Hulme, A., \& Shield, L. (2007). An overview of mobile assisted language learning: Can mobile devices support collaborative practice in speaking and listening? Retrieved January 5, 2019, from http://vsportal2007.googlepages.com/Kukulska_Hulme_and_Shield_2007.pdf

Kukulska - Hulme, A., Lee, H., \& Norris, L. (2017). 15 Mobile Learning Revolution: Implications for Language Pedagogy. The Handbook of Technology and Second Language Teaching and Learning, 217.

Kukulska-Hulme, A., Sharples, M., Milrad, M., Arnedillo-Sánchez, I., \& Vavoula, G. (2009). Innovation in mobile learning: A European perspective. International Journal of Mobile and Blended Learning (IJMBL), $1(1), 13-35$ 
Luís, A. R. (2018, March). Perceptions of the Educational Benefits of Mobile Devices in Language Teaching and Learning. In World Conference on Information Systems and Technologies (pp. 1406-1415). Springer, Cham.

McCarty, S., Sato, T., \& Obari, H. (2017). Mobile Language Learning Pedagogy: A Sociocultural Perspective. In Implementing Mobile Language Learning Technologies in Japan (pp. 19-32). Springer, Singapore.

Miangah, T. M., \& Nezarat, A. (2012). Mobile-assisted language learning. International Journal of Distributed and Parallel Systems, 3(1), 309.

Plana, M. G. C., Escofet, M. I. G., Figueras, I. T., Gimeno, A., Appel, C., \& Hopkins, J. (2013). Improving learners' reading skills through instant short messages: A sample study using WhatsApp.

Rosell-Aguilar, F. (2018). Autonomous language learning through a mobile application: a user evaluation of the busuu app. Computer Assisted Language Learning, 1-28.

Schroeder, S. (2011). Mobile games dominate smartphone app usage [STATS]. Retrieved January 6, 2019, from from http://mashable.com/2011/07/07/smartphone-mobile-games/.

Sha, L., Looi, C. K., Chen, W., \& Zhang, B. H. (2012). Understanding mobile learning from the perspective of self - regulated learning. Journal of Computer Assisted Learning, 28(4), 366-378.

Stockwell, G. (2013). Tracking learner usage of mobile phones for language learning outside of the classroom. CALICO Journal, 30(1), 118-136.

Stockwell, G., \& Hubbard, P. (2013). Some emerging principles for mobile-assisted language learning. The International Research Foundation for English Language Education, 1-15.

Tindell, D. R., \& Bohlander, R. W. (2012). The use and abuse of cell phones and text messaging in the classroom: A survey of college students. College Teaching, 60(1), 1-9.

Vesselinov, R., \& Grego, J. (2012). Duolingo effectiveness study. City University of New York, USA, 28. 